\title{
Covering Performers, Discovering Femininities: US Hip-Hop Journalism and Female Artists
}

\author{
Barbara Panuzzo \\ London South Bank University \\ barbiebabe@libero.it
}

\begin{abstract}
This article examines female performative identities as portrayed in the hip-hop press. The research approach is based on discourse analysis of selected texts in US hip-hop magazines, as well as of qualitative interviews with their main editors. On this basis, the article investigates the editorial practices that appear to inform hip-hop female performative identities in relation to the commercial strategies of artists and record companies. Female artists occupy scarce and hypersexualised space within the hip-hop press. This suggests the existence of underlying editorial and marketing agendas which perpetuate mythologised discourses of gender and race. The evidence shows that hip-hop editorial strategies are co-opted by interdependent commercial interests of the press and music industry. Significantly, female performers appear to be complicit in their journalistic positioning through the mediation of femininities which jeopardise their artistic authenticity.
\end{abstract}

Keywords: hip-hop, music press, performative identity, gender, race

\section{Performative positions of femininity in hip-hop journalism}

US hip-hop journalism emerged in the late 1970s from a necessity to document the rapidly growing phenomenon of hip-hop culture, thus evolving alongside it to become a blueprint for hip-hop magazines all over the world (Wang 2006). Hip-hop and its artists have been widely covered in a variety of publications ranging from underground music fanzines to popular press to news broadsheet, however the analysis of the specific editorial treatment of performers emerges as a gap within hip-hop scholarship (Cepeda 2004; Chang 2002; Forman 1995; McLeod 2002; Pough 2004) and music criticism (Fenster 2002; Laing 2006; Nunes 2010; Shuker 2001, 2005). This article investigates therefore the gender and racial traits of female performative identity in hip-hop journalism, as emerging from the narrative and pictorial coverage analysed in selected magazines. Drawing on Judith Butler's work, performative identity is intended here as a socially powerful discursive articulation (Butler 1990, 1993). Furthermore, this article evaluates the editorial strategies that appear to inform hip-hop femininities by drawing on qualitative interviews conducted with their main editors and journalists from selected publications, who prefer not to be identified by name in this article.

The normative gender positioning that relegates women to the role of hip-hop's second class citizens, widely debated within hip-hop scholarship (George 1998; Pough 2004; Rose 1994; Sharpley-Whiting 2007), emerges from this research as also characteristic of the hip-hop press. A review of US hip-hop magazines, both in print and online, unearths a distinct lack of female artists from front covers, editorial features and 
interviews. Moreover, the space that female performers occupy in this specialist press appears to be mediated through mythologised gendered posturing which ranges from aggressive masculinity to hyper-sexuality. Such stereotyped representations of femininity, and the level of female performers' involvement with these, is an aspect often debated academically in the context of rap music and video production, but rarely analysed within the texts of hip-hop journalism (Pough 2004; Rose 1994, 2008; SharpleyWhiting 2007).

Despite the widely recognised success of female hip-hop performers, their coverage in the hip-hop press emerges from this research to be recurrently facilitated by their inclusion in male-dominated rap crews - evidence of which can be found on the front covers of magazines such as Rap Pages (http://lovexlife.com/the-10-greatest-hip-hopmagazine-covers/) and Downlow (http://www.downmagazine.biz/backissues.html). This gender dialogue is a technique that visually translates the attempt of female MCs such as Lil' Kim and Foxy Brown to claim their place within rap music by adopting an aggressively masculine performative attitude aimed, as explained by Rose (1994) and Pough (2004), at rivalling their male counterparts. I argue that the strategic value of such gender positioning could however be rooted in the cultural conditioning specific to hiphop, where female members of male-based rap collectives are appreciated for the unique musical and visual aesthetics they contribute, and therefore is more complex than a competitive dialogical response. Conversely, when female artists are visually portrayed alongside male rappers, they appear to be mediated through an objectifying sexual positioning. Here, the female body functions as a semiotic reference to the sexual prowess of the male artist who is indeed the true, sole subject of the cover. The female subject is deployed as a prop to deliver a visual message based on the male rapper's dominant heterosexual identity and, by extension, Black masculinity (Sharpley-Whiting 2007). These images are constructed to be looked at through the male gaze, thus demonstrating an underlying gender asymmetry in line with Mulvey's interpretation of the implied gendering of the gaze (Mulvey 1989). According to Mulvey, the male gaze occurs when the audience of a media text is deliberately put in the perspective of a heterosexual man. In light of this, when a woman consumes the performance of a female hip-hop artist, she may do so through the eyes of a man, and through a masculine construction of feminine identity. Ultimately, I argue, the male gaze normalises the traits of womanhood it mediates with the help of the female artist and audience who conform to the hegemonic power established in this process. The most immediate consequence of the male gaze when applied to the mediation of hip-hop cultural texts is that it takes precedence over the female gaze, which is ultimately added to the media consumption as an ulterior layer of interpretation. It can be argued, however, that female artists also consciously derive pleasure from the gazed articulations of gendered performativity, as evidenced in the agentive reclamation of hyper-sexuality at the hands of numerous female rappers (Morgan 1999)

Ozone magazine also features sexually gazed female artists in its pages. Although the vast majority of its front covers feature male rappers, coverage of female hip-hop performers comes in two distinct categories: the quirky, efficient interviews with notable female hip-hop artists and the brief Dollar Menu features. These report the stories of hiphop video vixens and strippers from a professional, more humane perspective supported by booty shots that border on pornographic. These sexually revealing pictures appear to function, however, as a visual tool to appeal to the magazine's audience as they overtly frame women in the context of hip-hop pornography. The connection between hip-hop magazine audiences, which are mostly identified as young and male, and their interest in provocatively-clad female bodies is made by several editorial staff interviewed for this research, and will be explored further in this article in relation to gendered editorial strategies of hip-hop journalism.

The October 1999 issue of Notorious magazine, P. Diddy's contribution to hip-hop specialist press, dedicated a front cover and feature interview to Jennifer Lopez which 
exemplifies another gendered gaze approach to hip-hop press female coverage ( $P$. Diddy 1999). The front cover proposes an imaginative Renaissance-themed portrait of the Latina R\&B crooner/movie actress. The artist is pictured in her full height, completely naked but for her arms modestly covering her breasts and a pair of oversized white wings, the corner of one gently sloping to shelter her nudity from full view. The accompanying caption reads "The Angel Bares All to Puff Daddy", thus linking the interview topic with the cover theme. Although tasteful in its use of almost complete nudity, the pictorial representation of Jennifer Lopez is articulated through a male gaze (Mulvey 1975) as it clearly plays on the artist's sexuality to appeal to male readers. This is achieved by creating an unusual association of the trope of assertive female sexuality conveyed by her naked body with the contrasting ideal of purity represented by the angel reference. This contrast is reinforced by the wet shine of Jennifer Lopez's skin, a visual execution reminiscent of pornographic techniques. Moreover, the context set by the Renaissance-themed background and pose can be perceived to signify the appropriation and counter-hegemonic use of the traditional ideal of Raphaelite femininity in a modernday key. However, the corresponding editorial feature appears less sophisticated, with a mock-mysterious tone of delivery of the exclusive interview. The interview discusses the artist's musical and film acting projects, however, as the tone of the inquiring grows progressively intimate so do the questions regarding her taste in men, sexual preferences and private relationships. This shifts the focus of the interview from Jennifer Lopez's artistry to her relevance to politics of male desire - a strategy that validates her journalistic coverage through a narrative male gaze:

PD: Yeah, you're a tough interview. I just want to say, you have a beautiful ass.

JL: [Laughs] You're an idiot.

PD: I know you hate when people bring that up, but for real, you do have a beautiful ass.

JL: How would you know?

PD: I mean I've looked at it like every other man in America has looked at it. It's really not that big though. You know what I'm saying. It just fits your body perfectly. It's the perfect ass. (Jennifer Lopez quoted in P. Diddy 1999)

Although the exchange is purposely laden with subtext to openly define the mocksecret relationship between interviewer and interviewee, P. Diddy's specific reference to her backside exemplifies the way in which this narrative male gaze objectifies the artist. Lopez's articulation of dissent ("You're an idiot"), although significant in this dynamic, is rendered complicit by the playful delivery ("Laughs"). Moreover, the mention of Jennifer Lopez's backside in relation to male sexual desire places her at the centre of a strategy of fetishisation of the female body that is, I argue, ethnically ambiguous. In order to offer an ethnocentric perspective to the discourses of hip-hop gendered identity discussed so far, I draw from Sharpley-Whiting's (2007) racially-specific interpretation of hip-hop gendered performativity. Here, she identifies a post-colonial hegemonic hierarchy of beauty which she believes determines the racial traits appropriated and communicated by female hip-hop artists in order to gain mainstream recognition in the industry. Sharpley-Whiting places at the top of this hierarchy, borrowing the expression coined by New York Times columnist Ruth La Ferla, the "ethnically ambiguous" woman whose exotic racial mix escapes identification (2007: 30). Sharpley-Whiting argues that the notion of hip-hop femininity is visually personified in a perceived ethnic ambiguity of the performer, which combines a hypersexual attitude and curvaceous body frame - racially marked Black - with hegemonic standards of beauty - racially marked White. According to Sharpley-Whiting, although ethnically ambiguous women are evaluated against a standard of White hegemonic physical beauty, the inclusion of varying degrees of Blackness creates a fertile ground to racialise the politics of sexuality. However, she argues, it is important to note that this ideal of White beauty/Black sexuality is brokered by the perceived desires of Black men and cultivated as a by-product of Blackness. On this basis, I argue, this ideal is recuperated as an authentic hip-hop discourse in marketing that addresses a racially diversified audience. This fits with the wider sexist 
approach of music and women's magazines where elements of racially ambiguous overt sexuality are key to hefty sales figures. This strategy is similarly highlighted in the studies of women's lifestyle publications, sexuality and consumerism conducted by critics such as Eldridge (2009), Greer (1999) and McRobbie (1999). However, it puts in jeopardy the professionalism in the tone of the interview and, more importantly, it implicitly objectifies the female artist as a prop to the male interviewer/editor.

Another magazine rich in original artists' interviews and features is Murder Dog, which continues to successfully round up underground and mainstream artists since the mid1990s to review their musical output with narrative depth. Although Murder Dog's coverage of hardcore rap places by default female hip-hop artists in a minority when compared to the presence of their male counterparts within this music scene, it offers an insightful perspective on female coverage - as in the 2002 interview feature dedicated to female rapper Trina (Sonzala and Miami Mac 2002). Matt Sonzala and Miami Mac, authors of the interview, ask the artist whether she is under pressure (implicitly, from her record company) to deliver a performance aligned with a marked masculine positioning or assertive use of sexuality. As demonstrated in this article, this trend appears to apply to women in the industry, in contrast to the larger need for most male rappers to tone their performance down to mediate a more commercially viable product. Trina's reply begins as a clarification of her label's need to produce authenticity in her sound and performance:

With my label the first thing they say is we gotta give what you came out giving. This is what people want to see, they want to hear you just be raw. They want to see me stand up for the women, basically talk shit. (Sonzala and Miami Mac 2002).

Trina's comment is indicative of a commercial awareness in relation to the mediation of specific discourses of gendered identity. Her words acquire particular relevance when applied to the declared agency within her performative output. This raises a question regarding the source of the artist's perception - whether self-informed or commercially learnt - of what type of content and imagery appeal to the audience in a gender-specific manner. The implications of this consumerist consciousness on behalf of female artists will be further addressed in this article, in the commercial context of the music, media and marketing industries.

The range of female performative identities portrayed in the hip-hop press as sexualised subjects also encompasses positions of femininity which indicate complex forms of resistance to gender stereotypes. To illustrate this, I refer to the November 2010 joint opinion piece on Nicki Minaj's debut album published in the Village Voice (Baron and Juzwiak 2010). Although also rooted in the hip-hop music scene, the Village Voice is a cultural weekly that carries a tradition of analytical and critical journalism which sets it aside from the marked reliance on promotional tactics displayed by commercial hiphop specialist press titles. Nicki Minaj's feature, accessed via the Village Voice online magazine (www.vibe.com), is supported by a Japanese warrior-style portrait picture of the artist. This displays a striking use of iconoclastic imagery that borrows from several fields of cultural reference from superheroes to Barbie dolls to anime comics. The feature reads as an unenthusiastic album review somewhat balanced by an overall positive critique of the artist's wider work and unique performative identity. Co-author Zach Baron admires her capacity to ironically combine

[...] all these contradictory and self-contained identities ... [such as] the Queens girl she is by birth, the Valley Girl she is by ironic comment, the rap monster she is by ambition, the theatre student she is by inclination [...]. (Baron and Juzwiak 2010: 4)

Whilst Nicki Minaj's innovative approach to rap performance and female performativity is not lost on the authors, they manifest doubts on her mediated sexual positioning which Baron defines as "pneumatic asexuality - she is not a very convincing gay dude, sure, but ain't exactly heteronormative either [...]" (Baron and Juzwiak 2010: 4). The female rapper's peculiar brand of mediated sexuality is described as escaping both ends of the normative spectrum - homo and hetero. However, rather than being exalted in its 
uniqueness, her sexualised identity is denied in the word 'asexual'. I argue that such journalistic depiction of Nicki Minaj translates as a type of restrictive subject positioning that is further extended to her labelling as a 'sell-out' rap performer - due to the R\&B sounds combined with her MCing. The innovative appropriation of progressive sounds that Nicki Minaj proposes in her first record could be read, on the contrary, as a sign of her entrepreneurial attitude to the changing musical landscape of hip-hop, where numerous contemporary female artists are crossing over subgenre lines to engage with the changing tastes of a changing audience. Similarly, Nicki Minaj's own brand of feminine identity is innovative in her subversive embracing of the highly stylised, cartoonish image which frequently normalises hip-hop womanhood in the pages of the hip-hop press. In this context, her identity is constructed on the visual embodiment of a cartoon character - a strategy, which pushes the discursive boundaries of simulated artifice in the fully dimensional enactment of a flat gender stereotype. This allows a stereotyped identity to come to life through its embodiment, which in turn creates new meaning through such discourse.

A reference to normative positions of hip-hop femininities is also found in the editorial feature covering Nicki Minaj in the July 2010 issue of VIBE (O'Connor 2010). The artist is featured in one of the two split front covers of the magazine - the other going to R\&B and soul singer Erykah Badu - and interviewed at length in typical VIBE fashion (comprehensive and detailed long-form interviews). The front cover is a high impact shot of Nicki Minaj impersonating a larger-than-life anime character, wearing a cartoonish white and pink outfit that combines the bodice of a sexy waitress uniform with huge Disney princess-like puffed up sleeves and pink latex knee-high boots; the artist assumes a simple yet commandeering wide-legged pose, with both hands resting squarely on her hips, her head slightly inclined to the side, and her lips parted in a tonguelicking-lips pout. The anime theme is created by the little cartoon characters drawn in the background, and is maintained throughout the feature as a common element to all photographs included. These again show Nicki Minaj impersonating different cartoonish characters with an array of brightly coloured wigs, doll-like outfits and startled poses. In line with VIBE's wider cultural sensitivity, each outfit is annotated on the page in the manner of inspirational fashion magazines, thus hinting at a similar behaviour on the part of the publication's readers and their interest in fashion. In the editorial penned by Siobhan O'Connor (2010), the narrative sequences are interspersed with interview fragments. This creates a sensitive, non-judgmental context to frame what is perceived as an intimate, honest conversation between artist and journalist. The themed photo shoot is a clear link to Nicki Minaj's appropriation of several self-invented characters as part of her multiple performative identities, indicating her intent to humanise the Black Barbie doll imagery in a way that challenges traditional racial signifiers such as hair colour, skin complexion and body shape. This appears as an attempt to creatively combine the normative standards of White beauty exemplified in a Barbie doll representation that visualises a dominant representation of Black femininity. I argue that the merging of these gender and race discourses creates an innovative discourse in itself - an original take on the mediation of ethnic ambiguity (La Ferla 2003; Sharpley-Whiting 2007) - which functions as a tool of performative resistance of the very same discourses it stems from. Nonetheless, in so doing Nicki Minaj seems to also amplify the visual connotation of a Black skin fetish. Drawing from Mercer's analysis of the visual reproduction of racial fetishism within photography, the assembled symbolic imagery Nicki Minaj mediates can be interpreted as "a cultural artefact that says something about certain ways in which White people 'look' at Black people" (Mercer 1994: 435). Nicki Minaj's race-specific appropriation of a Black skin fetish can therefore be interpreted as its very own resistance, mediated through the innovative discourse that is her gendered performative identity. In light of this, the inclusion of Nicki Minaj within the landscape of female rappers appears to be validated by the fetish value of the racially-specific hypersexuality of her mediatised identity. 
Despite the variety of female performative identities that populate hip-hop culture, their journalistic portrayals that have emerged from this analysis appear to deploy a formulaic range of narratives and imagery. The female body appears to be largely mediated through the desire of the male gaze that objectifies it by deploying mythological imagery of sexualised assets. Female artists often appear to embrace, through images and words, the mediation of normative gender positions of hyper-sexualisation. In this context, the objectification of the female body is mediated in racially-specific terms which functions within the parameters of post-colonial hegemonic beauty standards. These complex gender and race discourses communicated within hip-hop journalism appear to fuel the tension between editorial production and audience consumption, as a commercial pressure for the artists to subscribe to profitable populist stereotypes emerges from the evidence gathered. These discourses, however, are further complicated by the agentive positioning of female artists in the process of identity articulation and mediation. As the cultural value placed on the real and authentic in hiphop by default impedes transparency in the media approach to female performers, I argue that the performative line between marketing necessity and artistic agency is often willingly blurred by the self-appointed custodians of media gateways such as hip-hop editors and journalists. The editorial strategies that inform such productions of mediated femininities will therefore be analysed in the following section in relation to the industrydriven editorial agendas behind the hip-hop press.

\section{Sustaining profitable press mediations of hip-hop femininities}

The coverage of female hip-hop performers within the hip-hop press appears to be scarce and reliant on hyper-sexual imagery. This indicates an imbalance between the musical production of female artists and their mediated presence. This article investigates therefore the gendered editorial politics that may inform this, through explorative interviews with hip-hop magazines' editorial staff. The majority of the editors and journalists interviewed in this research express the view that hip-hop culture is in shortage of good enough female artists to warrant journalistic coverage. An alleged lack of female hip-hop artists worthy of journalistic coverage is denounced by Anthony, editorin-chief of an established hip-hop magazine - the covers of which are liberally graced by scantily-clad video vixens. When called to comment on the aspects of female performance he documents in his publication, he states that:

Over the years we have not had as many female rappers as I would have liked. I remember

Gangsta Boo, Mia X, Hard Kaur and not too many more come to my memory [...] Females represent a powerful part of hip-hop. Yet sometimes it's hard to find female rappers that are doing the real job on the mic. (Anthony 2009)

Anthony's recognition of the artistic weight of female rappers in hip-hop is immediately contradicted by his difficulty in identifying artists who fit this category. Significantly, the implied criteria that defines such categorization hinges on a perceived lack of female rappers' ability to do the real job. The recourse to the theme of female rappers' authenticity is deployed here dialogically in comparison to their male counterparts, thus compounding the pictorial treatment of female artists evidenced earlier in this article. As Elafros observes, this strategy fits within a recurrent debate that requires females in hiphop "to redefine authenticity in more pro-woman ways" (Elafros 2007: 208). In light of this, I argue that the emerging normative dissociation of female artists from the real, as mediated editorially in the hip-hop press, hinders the production of feminine alternatives to patriarchal representations. Alongside the comparative lack of female versus male artists, the editorial staff interviewed recurrently cites the largely hetero-normative positioning of the artist and the perception of the audience's demand as the main editorial considerations behind the quality of female coverage. Andrew, veteran hip-hop journalist and editor of a contemporary hip-hop monthly, captures all three elements:

Obviously the new VIBE magazine has Nicki Minaj on the cover, but like I said, once again it's a certain type of female artist, that is going to appeal to the core audience. [...] And hip- 
hop, it's a reflection of society in that once again it's male driven. While it is mostly AfricanAmerican music, seventy percent of the buying public are still White Caucasian. So nonetheless their tastes will dictate to a degree exactly what winds up in the magazine. And I think what you're seeing appear in the magazines is a reflection of what both the editors think their audience want, what the writers think the editors want. (Andrew 2010)

Andrew makes a clear point regarding the perception of hip-hop's primary audience in terms of gender and racial makeup, and how this directly informs the editorial treatment of female artists in particular. This is based on the writers' and editors' perception of what type of female performer this mostly male, seventy percent White Caucasian audience consuming a Black musical production is interested in. This presupposition becomes particularly impactful in the attribution of a voyeuristic quality to the audience's consumption (Rose 2008; Thornham 2007). This discourse is further compounded by the strategic visual mediation of female sexuality which emerges in the pages of hip-hop magazines. Anthony, for instance, recognises that the secret to the longevity of his publication lies in the female eye candy that dominates its pages:

I think without sexuality a magazine has a hard time in hip-hop. There are two elements a magazine must subscribe to in this fickle environment: violence or sex. After a few years of covering gangsterism I preferred covering sex in the magazine. (Anthony 2009)

Anthony's words illustrate that the key to a successful hip-hop magazine is found in the balance of artistic coverage with ghetto tales and 'T\&As' (the common hip-hop slang for 'tits and ass'). Although the glamorisation of violent and sexual content is largely acknowledged to have a positive effect on record, video and magazine sales (Eldridge 2009), the line between implementing acceptable levels of sexuality and shaping editorial strategies at large appears to be blurred. Therefore, the standardisation of such editorial strategies into media practice informs a biased perception of female hip-hop performers' artistic authenticity. The emerging implication of the commercial pressure female artists are under to fit within mediated stereotypes of gendered authenticity is a recurrent issue within hip-hop journalism, as demonstrated in Trina's Murder Dog interview previously discussed (Sonzala and Miami Mac 2002). This editorial vision is in line with the contemporary journalistic as well as the wider media output, where hefty percentages of forecast sales and viewings are delivered against the generous display of female physical beauty (Eldridge 2009; Gill 2008). The link between commercial agendas and the pictorial use of female sexuality is substantiated by Andrew's comments on the editorial gendering of hip-hop magazines, which he also identifies as a trend affecting the wider journalistic industry:

And l've worked at larger magazines that were very commercially driven [...] lads' mags in the vein of Maxim who were driven by the presence of females on the cover. [...] Unless it's a special magazine created for women or there's some special effort in order to include them [...] l've been around and seen how if you're trying to appeal to a younger male, the female is being used in order to lure them to the news stand, but it's certainly not in a way which is sort of championing women or their rights or their achievements. It's more of a dangled carrot in order to get you to buy the issue. (Andrew 2010)

What emerges from Andrew's words is a clear connection between the setting of a commercial agenda based on the (perceived) target audience of the magazine and the coverage of female artists. The advertising content that is predominant within specialist hip-hop magazines appears to support such a perception of the audience's gender skew, as suggested by the abundance of alcohol and tobacco products, male urban sportswear and pornographic classifieds promoted in these publications. In this context, the element of male appeal becomes pivotal to the visual coverage of women who are contextually marginalised, yet deployed as the visual focal point to attract male sales. Maria, founder and editor-in-chief of a long-standing print and digital hip-hop magazine, denies the existence of underlying gender politics in the editorial strategy behind the coverage of hip-hop artists:

I mean, most female artists that you hear have steady rhymes, but their rhymes are not really something that a female would really say because it's a guy writing for them, so...We 
write about who people wanna read about so to me it's like, um, I would never dream of looking at an artist and say, well, you know, she's a female so l'm not gonna cover her or, um, she's a female so I can't cover her. It's not about the gender but more about, you know, do people care about this artist? And unfortunately, you know, there's not that many female artists that people wanna read about. (Maria 2010)

Maria's comments point to a simplistic yet twisted explanation of a demand/supply mechanism to justify the gender-based discrimination policy that appears to be deeply rooted within hip-hop journalism. According to her, female rappers are technically skilled but their lyrical content is not authentic, due to an allegedly generic male authorship and therefore not appealing to the magazine's audience. I argue, however, that the presumed gender preference on the audience's part may well be cemented by these very same gendered editorial decisions, and as such be its consequence rather than justification. In contrast to the lack of appeal of female rappers, Maria's use of almost pornographic pictures in her magazine points, again, to the objectification of the female body to serve a commercial purpose.

The gender policing emerging from the editors' and journalists' comments appears to be less marked across VIBE magazine which tends to feature female artists more than its competitors. However, a gendered editorial strategy is found in the instrumental use of VIBE's front covers to generate tactical controversies. An example of this is the debate of the September/October 2008 cover that featured hip-hop artist Ciara (Smith 2008). The front cover caption reads "Stand Up! Ciara" and is followed by a quote from the artist that reads "I'm NOT GONNA HOLD BACK too much". The poignancy of the bigger font utilised to highlight part of the quote creates a textual reference to the accompanying picture. The singer dominates the page in a provocative crouching pose, wearing only a pair of high-heeled shoes and her hair long over her shoulders. Ciara reportedly claimed to have been wearing underwear during the shoot which was, allegedly unbeknownst to her, airbrushed out. VIBEs former editor-in-chief Danyel Smith stepped in to clarify that the singer actually pitched the magazine for the cover, was naked during the photo shoot and fully aware of its artistic concept. Although the magazine was never sued, the drama that it generated brought both Ciara and VIBE to the forefront of public awareness in a mutually convenient fashion, at a time when Ciara was ready to launch her new artistic project (Harris 2008).

As editor-in-chief Anthony bluntly commented on the strategies at play in the editorial selection of cover artists, "most covers in this industry are paid for; if they tell you otherwise they are lying" (Anthony 2009: 2). Front covers appear to function as a mediatised space where relationships between magazine and artist are brokered and forged, to mutually benefit from the boost in sales that public controversy is likely to generate. This leads to the assumption, I argue, that the concept behind most front covers is indeed largely masterminded by the creative team behind the artist. When discussing this insight with freelance music journalist Mark, he corroborated the point:

But more often than not [the photo shoots] they're especially commissioned by the label to use for international press, so the label shoots the artist, and their creative team, working with the photographer to come up with a look, will have complete control over how that artist is portrayed and positioned and what they look like. (Mark 2009)

Mark explicitly observes that the record company behind the artist has an interest in commissioning a photo shoot to use in the press which, I argue, reinforces Anthony's previous point regarding the strategic purchase of front covers as a marketing tool. Although the record company works together with the magazine's creative team, they ultimately own the way the artist is portrayed. Moreover, Mark suggests that there is a strong connection, at least from a visual perspective, between the concept of the feature and the imagery chosen to accompany it in relation to the artist's willing interpretation of a specific performative identity:

So to get back to the point of who influences who, I think the artist ultimately is responsible for how they are perceived visually. They are not responsible for how they are perceived in text because they don't get to see pieces before they are printed in the main. [...] So you 
know, artists are in control of how they are perceived to a greater degree than they would like us to believe and photographs in particular they are in a lot of control over. (Mark 2009)

According to Mark, artists are highly involved in their mediated visual representation, alongside their record company. However, they do not necessarily like to be perceived as such. This could be so that the artists create a buffer between their own representation and the audience's reaction to it, or simply so that lucrative tactical controversies between artist and magazine can be generated, as highlighted by McLeod (2002) and evidenced in VIBE's front cover of Ciara. However, it is difficult to gauge the level of the record company's predetermined marketing strategy on the quality of the journalistic coverage. In this regard, journalist and editor Andrew comments on the input of artists' management teams and/or record companies in the degree of exposure that is sought on the artists' behalf. In his view, this is accepted or rejected by magazines on the basis of their overarching media relationships, or the relevance of the artists within the musical landscape, or even as a means to gain access to the artist (Andrew 2010). However, the assumption behind the use of magazine front covers as a paid-for commercial tool, despite clearly being a scalable commercial opportunity, is met by most of the editors and journalists interviewed with either a flat refusal or honest admission. Andrew offers some useful insight on the issue:

I know that that [paying for a front cover] has happened, and does happen with bigger magazines. You have to be talking about having a million, two million readers in order to make it worthwhile paying someone so that you can get their story. [...] l've had people call me when I worked at this other more commercial magazine, ask me how much it costs to get an article, so I know there are certain editors out there who will not only pay someone to get their article, but will take money from someone less interesting in order to publish a piece on them. So it works both ways. (Andrew 2010)

The very same refusal of some editors to comment on the topic of front cover transactions, I argue, represents a telltale sign of the existence of this practice. Andrew's and, previously, Anthony's open admission to this are equally indicative of the scale and frequency of such custom. As Andrew observes, pay-for front covers serve a mutual commercial purpose to magazines and record companies alike. Most importantly, this practice appears to directly inform the editorial criteria in the commissioning process purely on a financial basis. Jane (2010), a hip-hop journalist previously affiliated with, amongst many others, the Village Voice and VIBE magazines, offers insightful comments on the gendered editorial strategies of the hip-hop press. She broadly identifies two thematic strands that provide a solid opportunity to have a piece published in a hip-hop magazine, particularly to cover a female artist:

Some publications would often have women write about female artists, but not all. [...] I could have done good pieces about many other male artists. [...] A lot of times I didn't get that opportunity because I was more critical of the artists than other writers were. [...] Whether it's hip-hop or rock or opera, music magazines are part of a publicity machine...And if you don't see yourself that way, or if you don't want to participate in that, it becomes harder to get assignments. (Jane 2010).

Significantly, if the piece is designed to feature an established female artist, a female writer is usually preferred to carry the assignment, presumably on the basis of approaching the article/interview from a fellow gender perspective in order to gain deeper insight. However, Jane explains that the adoption of a critical angle in the writing of a feature, particularly with regards to the coverage of male artists, constitutes a barrier to having the piece published. This, I argue on the basis of the evidence so far reviewed, is because the article is ultimately designed to function as a publicity tool for the artist, thus helping maintain a collaborative relationship between the magazine and the performer (or the management teams and/or record companies representing them). As Jane suggests, this configuration is further complicated by the gendered positioning of female editors and journalists in the hip-hop press:

What's striking to me is there are still a lot of women working at a lot of these publications.

I think XXL maybe has a female Editor-in-Chief, The Source had a female Editor-in-Chief, 
VIBE had a female Editor-in-Chief. But in general those women tend to [...] identify more with the male gaze either because they feel like that's the only way for them to succeed financially or because they're just really not interested in women's issues. [...] You have to look at the careers of women who have been really vocal and dissident on a lot of these issues. Those women have not been promoted very often. (Jane 2010)

Jane's comments reinforce the insight that gender plays a significant role in the editorial processes which appear to privilege the selection of male artists' coverage - a strategy denounced by The Source's former Editor-in-Chief Kim Osorio in her exposé (2008) of the magazine's alleged discriminatory gender politics. The internal pressures amongst publishers, staff members and artists evidenced here appear to create an environment within which female editors are constrained to varying degrees. In this context, the recurrent presence of female editorial staff in mainstream hip-hop magazines is indicative of deep-seated discrimination that produces the derogatory portrayal of female artists.

\section{Conclusion}

This article has investigated the editorial treatment of female artists emerging from their visual and narrative portrayals in selected front covers and articles. Hip-hop magazines such as the Village Voice, VIBE and Rap Pages have offered mediations of female performative positions that combine aggressive masculine posturing with hypersexuality. The use of objectifying sexualised imagery, particularly in front covers, has emerged as a recurrent editorial strategy, which can strengthen the relationship between artist and media outlet through allegiance or controversy - a mutually beneficial result as they both generate public interest. The female body appears to be largely mediated through the desire of the male gaze that objectifies it by deploying mythologised discourses of gender and race. Female artists often appear to embrace, through images and words, the mediation of such normative gender positions. In this context, the objectification of the female body is mediated in terms of a racial-specific sexualisation which functions within the parameters of post-colonial hegemonic beauty standards.

Female artists appear to be increasingly consigned to brief, pornographic-style sections of hip-hop magazines, or entirely dropped off their pages. This particular insight constitutes the access point into the conversations that were conducted with hip-hop editors and journalists, in order to understand the wider editorial concerns behind the journalistic reproductions of specific discourses of hip-hop femininity. The scarcity and markedly graphic quality of this coverage is largely attributed by the editors to a perceived lack of artistic worth of female performers, which is evaluated dialogically on the basis of authentic male dexterity. This tactical approach is quoted as a justification to a perceived mechanism of demand/supply which is based on the young male demographic profile of hip-hop magazines' readers. Female sexuality is therefore commercially deployed through the appeal of hyper-sexual imagery which normalises specific stereotypes of race and gender that are then circulated within hip-hop culture and beyond. The complex gender and race discourses deployed in hip-hop journalism, compounded by the comments of the editors and journalists interviewed, indicate a commercial pressure for the artists to subscribe to profitable populist stereotypes. These discourses, however, are further complicated by the agentive positioning of female artists in the process of identity articulation and mediation. This is challenging, as female artists such as Nicki Minaj also perform hypersexual gender roles as a way to subvert patriarchal notions of femininity. This tactic is controversial within the hip-hop community; as a result the female artists are reluctant to overtly own up to their participation in these mediations. Importantly, this research provides evidence that female performers are complicit in the mediation of gender discourses that undermine their authentic positioning, thus extending the debate of hip-hop scholarship in relation to complex issues of female agency. 
The issue of the gender positioning of the corporate ownership of hip-hop media outlets, often analysed in the context of music production (Shuker 2005), is rarely extended to music journalism. Significantly, the evidence discussed in this article suggests that female journalists are privileged in the commissioning of articles on samegender artists, on the basis of providing a relevant, organic perspective to the tone of the feature. This editorial practice reinforces gender segregation in hip-hop journalism, which is further complicated by the presence of numerous female editors in the field. The recurrent use of sexually explicit imagery evidenced in this research indicates that female editors/journalists identify with the male gaze in their editorial positioning. As suggested by some of the editorial staff interviewed, this is potentially in line with the financial stability associated with the mediation of content that is sensitive to the politics of male desire. This particular configuration of editorial power relations in the hip-hop press calls for a further feminist analysis of the strategies that inform the allocation of coverage based on the gender compatibility between artist and journalist.

\section{References}

Baron, Z. and Juzwiak, R. 2010. Nicki Minaj's Pink Friday, Debated, in The Village Voice, 24 November 2010, http://www.villagevoice.com/2010-11-24/music/nickiminaj-s-pink-friday-debated/ Accessed: 4 September 2011.

Butler, J. -

1990. Gender Trouble: Feminism and the Subversion of Identity. London and New York: Routledge.

1993. Bodies That Matter. On the Discursive Limits of "Sex". New York: Routledge.

Cepeda, R. Ed. 2004. And It Don't Stop! The Best American Hip-Hop Journalism of the Last 25 Years. New York: Faber and Faber.

Chang, J. 2002. Word Power: A Brief, Highly Opinionated History of Hip-Hop Journalism. In Steve Jones Ed. Pop Music and the Press. Philadelphia: Temple University Press: 65-71.

Elafros, A. 2007. Are Female Rappers 'Authentic'? In Mickey Hess Ed. Icons of HipHop: An Encyclopedia of the Movement, Music, and Culture. Westport: Greenwood Press: 193-216.

Eldridge, A. 2009. Sex Sells: A Content Analysis of Women in Magazine Advertisements, Senior Seminar, 485, Dan Cronn-Mills, 03 May 2009, http://mavdisk.mnsu.edu/eldria/7A.htm Accessed: 31 March 2012.

Fenster, M. 2002. Consumers' Guides: The Political Economy of the Music Press and the Democracy of Critical Discourse. In Steve Jones Ed. Pop Music and the Press. Philadelphia: Temple University Press: 81-92.

Forman, M. 1995. Media Form and Cultural Space: Negotiating Rap "Fanzines". Journal of Popular Culture 29 (2): 171-188.

George, N. 1998. Hip-Hop America. New York: Penguin Books.

Gill, R. 2008. Empowerment/Sexism: Figuring Female Sexual Agency in Contemporary Advertising. Feminism \& Psychology 18 (1): 35-60.

Greer, G. 1999. The Whole Woman. London: Doubleday.

Harris, C. 2008. Ciara Was Nude in Photo Shoot, VIBE Editor Insists, http://www.mtv.com/news/articles/1594794/ciara-was-nude-photo-shoot-vibeeditor.jhtml Accessed: 23 October 2011.

La Ferla, R. 2003. Generation E.A.: Ethnically Ambiguous, New York Times, Fashion \& Style section, 28 December.

Laing, D. 2006. Anglo-American Music Journalism. In Andy Bennett, Barry Shank and Jason Toynbee, Jason Eds. The Popular Music Studies Reader. New York:

Routledge: 333-339. 
McLeod, K. 2002. The Politics and History of Hip-Hop Journalism. In Steve Jones Ed.

Pop Music and the Press. Philadelphia: Temple University Press: 156-167.

McRobbie, A. 1999. In the Culture Society. London: Routledge.

Mercer, K. 1994. Welcome to the Jungle: New Positions in Black Cultural Studies. New York: Routledge.

Morgan, J. 1999. When Chickenheads Come Home to Roost: My Life as a Hip-hop Feminist. New York: Simon and Schuster.

Mulvey, L. -

1975. Visual Pleasure and Narrative Cinema. Screen 16 (3): 16-18.

1989. Visual and Other Pleasures. Bloomington: Indiana University Press.

Nunes, P. 2010. Good Samaritans and Oblivious Cheerleaders: Ideologies of Portuguese Music Journalists Towards Portuguese Music. Popular Music 29 (1): 41 59.

O'Connor, S. 2010. Character Study. VIBE July 2010: 72-77, 106.

Osorio, K. 2008. Straight From The Source: An Exposé From the Former Editor In Chief of the Hip-hop Bible. New York: Simon and Schuster.

P. Diddy. 1999. Touched by an Angel, in Notorious October 1999. http://beyondbeautiful.com/topic/421/Notorious-Magazine-October-1999 Accessed: 7 September 2011.

Pough, G. 2004. Check It While I Wreck It: Black Womanhood, Hip-Hop Culture and the Public Sphere. New York: Northeastern University Press.

Rose, T. -

1994. Black Noise: Black Music and Black Culture in Contemporary America.

Hanover: Wesleyan University Press.

2008. The Hip-Hop Wars: What We Talk About When We Talk About Hip-Hop - and Why it Matters. New York: Basic Books.

Sharpley-Whiting, T. D. 2007. Pimps Up, Ho's Down: Hip-Hop's Hold on Young Black Women. New York: New York University Press.

Shuker, R. -

2001. Understanding Popular Music. New York: Routledge.

2005. Popular Music: The Key Concepts. London: Routledge.

Smith, D. 2008. Stand Up! Ciara. "I'm Not Gonna Hold Back Too Much". VIBE September/October 2008.

Sonzala, M. and Miami, M. 2002. Trina Interview, Murder Dog, Volume 9, Number 3, http://www.murderdog.com/archives/2002/trina.html Accessed: 12 February 2010.

Thornham, S. 2007. Women, Feminism and Media. Edinburgh: Edinburgh University Press.

Wang, O. 2006. Trapped in Between the Lines: The Aesthetics of Hip-Hop Journalism. In Jeff Chang Ed. Total Chaos: The Art and Aesthetics of Hip-Hop. New York: Basic Civitas: $165-174$.

\section{Interviews}

Andrew. 2010. Telephone interview by Barbara Panuzzo, 18 June.

Anthony. 2009. Online interview by Barbara Panuzzo, 10 September.

Jane. 2010. Telephone interview by Barbara Panuzzo, 27 September.

Maria. 2010. Telephone interview by Barbara Panuzzo, 10 May.

Mark. 2009. Face-to-face interview by Barbara Panuzzo, 28 October. 